\title{
A comparative study on changes in physical fitness characteristics of judo athletes according to their careers
}

\author{
Seo, Kyoungho ${ }^{\mathrm{a}}$ \& Seo, Tae-Beom ${ }^{\mathrm{b}^{*}}$ \\ ${ }^{a}$ Researcher, Center for Sport Science in Jeju \\ ${ }^{b}$ Professor, Department of Kinesiology, College of Natural Science, Jeju National University, Jeju, Korea
}

\begin{abstract}
The purpose of this study was to compare judo-related physical fitness, body composition, and isokinetic knee functions of male judo athletes from different age groups. Subjects for this study were thirty male judo athletes and randomly divided into three groups: cadet judo athletes (CJA, $n=10$ ), junior judo athletes (JJA, $\mathrm{n}=10$ ) and senior judo athletes (SJA, $\mathrm{n}=10$ ). Body composition, physical fitness, anaerobic wingate test, and isokinetic knee strength test were analyzed for comparing characteristics of judo athletes with age. Statistical analysis was performed using one-way ANOVA followed Scheffe post hoc test. As the result of this study, body weight and muscle mass were significantly higher in the SJA group than those in the CJA group. The SJA group had significantly higher sit-up, vertical jump, side step and sit-and-reach values than the CJA and JJA groups, and the JJA group had significantly higher sit-up and back strength values than the CJA group. The absolute values of peak power (PP) and average power (AP) and relative values of PP in the SJA group showed significant differences compared to the CJA and JJA groups. Therefore, present findings provided research evidence that anaerobic power, maximal muscle strength and endurance would positively regulate performance of judo athletes with increasing age and athletic experience. Coaches and trainers in the field should try to provide a periodic training program to improve judo-related physical fitness and succeed.
\end{abstract}

Key words: Judo athlete, Cadet, Physical fitness, Wingate test, Isokinetic function

\section{Introduction}

Judo is an Olympic combat sport requiring tactics, technique and physical fitness (Zhao et al., 2019; Lech et al., 2015). In judo competition, grip dispute is very important technique to break the balance and throw the

Submitted : 29 November 2021

Revised : 20 December 2021

Accepted : 27 December 2021

Correspondence : seotb@jejunu.ac.kr opponent to the ground (Franchini et al., 2019), and these techniques such as gripping the opponent's uniform and landing a fighter on a tatami mat is continuously performed for a duration of four minutes. In other words, maximum muscle strength and endurance as well as anaerobic power are essential to winning judo match (Casals et al., 2017). Branco et al. (2021) suggested that maximum muscular strength is a fundamental capacity to improve anaerobic power and 
muscular endurance of judo players (Ghrairi et al., 2014), developing this fitness by the periodic training program based on scientific evidence (Franchini et al., 2015; Marques et al., 2017). Another previous studies on performance-related fitness of judo athletes have been reported that junior athletes under 21 years of age showed higher relative performance compared to cadet athletes who is under 18 years of age, due to greater maximal isometric hand-grip strength, muscle endurance and anaerobic power in junior athletes (Agostinho et al., 2018; Franchini et al., 2014; Sterkowicz-Przybycien et al., 2017).

In addition, judo is also advantageous for athletes with strong muscular strength in a lower weight class because of a weight-categorized sport. Many researchers have studied various weight management programs to rapidly regulate percentage body fat and muscle mass over five to seven days according to gender, age and athletic experience (Artioli et al., 2010; Branco et al., 2021; Kons et al., 2017). And Torres-Luque et al. (2016) suggested that the highest performing male and female judo athletes should maintain an ideal body composition with approximately $10 \%$ and $16 \%$ body fat, respectively.

With these findings reported by previous studies, elite judo athletes must maintain an outstanding level of physical fitness and body composition, and assessment of athletes' physical condition is considered to be crucial in setting training goals. However, despite a lot of information needed to succeed as a judo athlete, no studies have been found that provide the criterion for maximum muscle strength, anaerobic power and muscular endurance as grade rise. Therefore, the aim of our research was to compare judo-related physical fitness, body composition and isokinetic knee functions of male judo athletes from different age. Our hypothesis was that anthropometric characteristics and physical variables would be statistically different between the age groups.

\section{Methods}

\section{Participants}

Thirty male judo athletes were taken part in this study and evaluated: cadet judo athletes (CJA, $n=10$ ), junior judo athletes (JJA, $n=10)$ and senior judo athletes (SJA, $\mathrm{n}=10$ ). Characteristics of participants were shown in Table 1. Before beginning the study, all participants had a detailed explanation of this study and submitted their written informed consent to researchers. This research was conducted ethically according to international guidelines.

\section{Methodology}

\section{Body composition analysis}

All participants visited to the center of sports science by 9:00 am with fasting for eight hours. Height and body weight were measured in light clothing and without wearing shoes using Jenix (DS-103M, Dong Sahn Jenix, Seoul, Korea) and body composition was measured by multi-frequency, whole-body bioimpedance device (Inbody 770, Inbody, Seoul, Korea) to confirm the body fat, body fat percentage ( $\%$ Fat $)$, muscle mass.

Table 1. Characteristics of the subjects

\begin{tabular}{lcccccc}
\hline \hline & CJA $^{\mathbf{a}}$ & JJA $^{\mathbf{b}}$ & SJA $^{\mathbf{c}}$ & $\boldsymbol{F}$ & $\boldsymbol{p}$ & Post-hoc \\
\hline Age (year) & $14.9 \pm 0.87$ & $17.9 \pm 0.73$ & $31.1 \pm 5.30$ & 75.767 & $.000^{* * *}$ & $\mathrm{a}<\mathrm{c}$ \\
Height (cm) & $167.23 \pm 10.88$ & $171.39 \pm 7.18$ & $175.84 \pm 11.64$ & 1.820 & .181 & $.000^{* * *}$ \\
Career (year) & $2.99 \pm 1.58$ & $4.77 \pm 1.07$ & $19.16 \pm 5.03$ & 81.207 & $\mathrm{a}<\mathrm{b}<\mathrm{c}$ \\
\hline \hline
\end{tabular}

Values are mean \pm Standard Deviation

CJA, cadet judo athletes; JJA, junior judo athletes; SJA, senior judo athletes

$* p<.05, * * p<.01, * * * p<.001$ 


\section{Physical fitness tests}

The physical fitness test was composed of sit-up, vertical jump, side step, reaction time, backward flexibility, sit-and-reach, grip strength, and back strength. For muscular endurance capacity, the sit-up was performed by lying on the floor and bending the knees for 60 seconds, and side step (ST-110, Seed Tech, Korea) was used for twenty seconds to examine anaerobic power and agility. The vertical jump (ST-150, Seed Tech, Korea), reaction time (ST-140, Seed Tech, Korea), backward flexibility (TKK-1860, Takei, Japan), sit-and-reach (TKK 5403, Takei, Japan), grip strength (TKK 5401, Takei, Japan) and back strength (TKK 5402, Takei, Japan) were measured twice, and we recorded at the highest value. All participants took a rest for three minutes after preliminary test and then measured physical fitness.

Anaerobic Wingate test

Wingate test was applied for investigating the maximum anaerobic capability using a Monark bicycle (Ergomedic 823E, Monark Exercise AB, Vansbro, Sweden). After three minutes of a cycling warm-up, judo athletes accelerated pedals as fast as possible for 30 seconds with the 'start' signal. The peak power (PP) means the highest anaerobic pedaling power, the average power (AP) is the speed-endurance ability, and the fatigue index (FI) is the fatigue resistance quantification.
Isokinetic knee strength test

Isokinetic muscle function of the knee extensors and flexors was measured using HUMAC NORM (Humac Norm 776, CSMi, Boston, USA). The maximal isokinetic muscle strength of the knee extension and flexion was performed at an angular velocity of $60 \% \mathrm{sec}$ and $180^{\circ} / \mathrm{sec}$, and repeated three times. To compare isokinetic muscle functions, we presented the relative value obtained by dividing the absolute value by the body weight.

\section{Statistics}

PASW (Statistical Package for Predictive Analytics Soft Ware) 18.0 program was used to confirm differences of maximum muscle strength and isokinetic knee muscle functions between groups. Statistical analysis was performed using one-way ANOVA followed Scheffe post hoc test, and All values are expressed as mean \pm standard deviation (SD). $p<0.05$ was considered significant.

\section{Results}

\section{Change in body composition according to age}

To examine difference in body composition from different age groups, we examined body weight, the body fat percentage (\%Fat), muscle mass using whole-body bioimpedance device. As shown in Table

Table 2. Body composition of judo athletes from different age group

\begin{tabular}{lcccccc}
\hline \hline & CJA $^{\mathbf{a}}$ & JJA $^{\mathbf{b}}$ & SJA $^{\mathbf{c}}$ & $\boldsymbol{F}$ & $\boldsymbol{p}$ & Post-hoc \\
\hline Weight (kg) & $62.80 \pm 14.03$ & $72.97 \pm 10.08$ & $90.29 \pm 26.93$ & 5.658 & $.009^{* *}$ & $\mathrm{a}<\mathrm{c}$ \\
BMI (kg/m²) & $22.27 \pm 3.37$ & $24.76 \pm 2.02$ & $28.56 \pm 4.40$ & 8.631 & $.001^{* *}$ & $\mathrm{a}<\mathrm{c}$ \\
Body fat (\%) & $16.45 \pm 7.14$ & $13.71 \pm 2.23$ & $17.15 \pm 6.07$ & 1.067 & .358 & \\
Muscle mass (kg) & $28.90 \pm 5.84$ & $35.72 \pm 4.55$ & $41.79 \pm 10.10$ & 7.947 & $.002^{* *}$ & $\mathrm{a}<\mathrm{c}$ \\
\hline \hline
\end{tabular}

Values are mean \pm Standard Deviation

CJA, cadet judo athletes; JJA, junior judo athletes; SJA, senior judo athletes

${ }^{*} p<.05, * * p<.01, * * * \quad p<.001$ 
Table 3. Physical fitness of judo athletes from different age group

\begin{tabular}{|c|c|c|c|c|c|c|}
\hline & CJA $^{a}$ & $\mathbf{J J A}^{\mathbf{b}}$ & SJA $^{\mathrm{c}}$ & $\boldsymbol{F}$ & $p$ & Post-hoc \\
\hline sit-up (count) & $47.7 \pm 4.16$ & $56.3 \pm 6.11$ & $57.7 \pm 6.49$ & 9.075 & $.001^{* *}$ & $\mathrm{a}<\mathrm{b}, \mathrm{c}$ \\
\hline vertical jump (cm) & $53.2 \pm 5.65$ & $54.4 \pm 3.34$ & $58.3 \pm 3.40$ & 3.901 & $.032^{*}$ & $a<c$ \\
\hline side step (count) & $40.7 \pm 4.08$ & $40.7 \pm 4.27$ & $47.9 \pm 3.17$ & 11.517 & $.000^{* * *}$ & $\mathrm{a}, \mathrm{b}<\mathrm{c}$ \\
\hline reaction-time (sec) & $0.291 \pm 0.039$ & $0.267 \pm 0.023$ & $0.271 \pm 0.027$ & 1.812 & .183 & \\
\hline backward flexibility (cm) & $49.27 \pm 6.99$ & $44.47 \pm 9.85$ & $47.90 \pm 8.77$ & .822 & .450 & \\
\hline sit-and-reach (cm) & $9.90 \pm 6.50$ & $15.25 \pm 9.36$ & $20.29 \pm 3.43$ & 5.711 & $.009^{* *}$ & $a<c$ \\
\hline grip-strength:L (kg) & $33.91 \pm 5.96$ & $41.54 \pm 5.14$ & $41.61 \pm 14.56$ & 2.143 & .137 & \\
\hline grip-strength:R (kg) & $35.79 \pm 8.47$ & $44.02 \pm 6.06$ & $42.86 \pm 9.44$ & 3.009 & .066 & \\
\hline back strength (kg) & $104.30 \pm 14.90$ & $135.85 \pm 14.69$ & $123.25 \pm 26.49$ & 4.445 & $.021^{*}$ & $a<b$ \\
\hline
\end{tabular}

Values are mean \pm Standard Deviation

CJA, cadet judo athletes; JJA, junior judo athletes; SJA, senior judo athletes

${ }^{*} p<.05, * * p<.01, * * * p<.001$

Table 4. Anaerobic power of judo athletes from different age group

\begin{tabular}{lcccccc}
\hline \hline & CJA $^{\mathbf{a}}$ & JJA $^{\mathbf{b}}$ & SJA $^{\mathbf{c}}$ & $\boldsymbol{F}$ & $\boldsymbol{p}$ & Post-hoc \\
\hline Fatigue index (\%) & $54.26 \pm 6.55$ & $60.72 \pm 8.26$ & $58.08 \pm 10.64$ & 1.409 & .262 & \\
Average power (W) & $351.10 \pm 82.52$ & $459.83 \pm 84.26$ & $604.11 \pm 128.81$ & 15.852 & $.000^{* * *}$ & $\mathrm{a}, \mathrm{b}<\mathrm{c}$ \\
Peak power (W) & $471.19 \pm 114.91$ & $636.58 \pm 131.48$ & $807.16 \pm 144.27$ & 16.500 & $.000^{* * *}$ & $\mathrm{a}, \mathrm{b}<\mathrm{c}$ \\
Average power (W/kg) & $5.58 \pm 0.79$ & $6.28 \pm 0.61$ & $6.87 \pm 0.95$ & 6.419 & $.005^{* *}$ & $\mathrm{a}<\mathrm{c}$ \\
Peak power (W/kg) & $7.51 \pm 1.21$ & $8.67 \pm 0.88$ & $9.23 \pm 1.53$ & 5.045 & $.014^{*}$ & $\mathrm{a}<\mathrm{c}$ \\
\hline \hline
\end{tabular}

Values are mean \pm Standard Deviation

CJA, cadet judo athletes; JJA, junior judo athletes; SJA, senior judo athletes

${ }^{*} p<.05,{ }^{* *} p<.01, * * * \quad p<.001$

2, body weight $(F=5.658, p=0.009)$, BMI $(F=8.631$, $p=0.001)$, and muscle mass $(F=7.947, p=0.002)$ were significantly higher in the SJA group than those in the CJA group. \%Fat $(F=1.067, p=0.358)$ showed no significant differences between groups.

Change in physical fitness according to age

Changes in judo related physical fitness, including muscular endurance, power, agility, flexibility and muscle strength, with age groups are shown in Table 3. The SJA group had significantly higher sit-up $(F=9.075, p=0.001)$, vertical jump $(F=3.901, p=0.032)$, side step $(F=11.517, \quad p=0.000)$ and sit-and-reach $(F=5.711, p=0.009)$ values than the CJA and JJA groups, and the JJA group had significantly higher sit-up $(F=9.075, p=0.001)$ and back strength $(F=4.445$, $p=0.021$ ) values than the CJA group.

Change in anaerobic power according to age

Wingate test is one of the most well-known methods for measuring anaerobic power. As shown in Table 4, absolute values of PP $(F=16.500, p=0.000)$ and AP $(\mathrm{F}=15.852, \mathrm{P}=0.000)$ and relative values of $\mathrm{PP}$ $(F=5.045, p=0.014)$ and AP $(F=6.419, p=0.005)$ in the SJA group showed significantly differences compared to the CJA and JJA groups. But there was no significant difference between all groups in FI. 
Change in isokinetic knee functions according to age

We performed isokinetic knee muscle testing at $60 \%$ sec and $180^{\circ} / \mathrm{sec}$ for identifying quadriceps and hamstring muscle strength and balance. As shown in Table 5, unlike relative peak torque at $60 \%$ sec, absolute peak value of isokinetic left $(F=6.713, p=0.004$; $F=5.083, \quad p=0.013)$ and right $(F=5.459, p=0.010$; $F=3.672, p=0.039$ ) knee extensor and flexor strength showed significant differences in the SJA group compared to CJA group. At the angular velocity of $180^{\circ} / \mathrm{sec}$, there was significant difference between groups in relative average power of isokinetic left $(F=3.533, p=0.043)$ and right $(F=3.403, p=0.048)$ knee flexor muscle.

\section{Discussion}

Because it is very important for judo athletes to determine their weight category for their success, many athletes are trying to lose weight through body fat reduction (Franchini et al., 2011; Torres-Luque et al., 2016). The ideal weight loss, which has a positive effect on judo performance, is known to decrease \%Fat and increase FFM (Casals et al., 2017; Clarys et al., 2011). Our study examined body composition of judo athletes from different age groups, and confirmed that body weight and FFM had a significant higher in the SJA group than those in the CJA group, but \%Fat showed no difference between groups. In previous studies on body composition and anthropometrical profile of judo athletes, arm circumference in male cadets was smaller than that of junior and senior judo athletes (Franchini

Table 5. Isokinetic knee muscle strength of judo athletes from different age group

\begin{tabular}{|c|c|c|c|c|c|c|c|}
\hline & & $\mathbf{C J A}^{\mathrm{a}}$ & $\mathrm{JJA}^{\mathrm{b}}$ & $\mathrm{SJA}^{\mathrm{c}}$ & $F$ & $p$ & Post-hoc \\
\hline \multirow{4}{*}{$\begin{array}{l}\text { PT at } 60^{\circ} / \mathrm{sec} \\
\text { (N.m) }\end{array}$} & L:extension & $142.80 \pm 34.50$ & $180.20 \pm 36.06$ & $188.50 \pm 12.56$ & 6.713 & $.004^{* *}$ & $a<b, c$ \\
\hline & L:flexion & $82.30 \pm 14.69$ & $88.90 \pm 16.04$ & $107.00 \pm 22.17$ & 5.083 & $.013^{*}$ & $\mathrm{a}<\mathrm{c}$ \\
\hline & R:extension & $143.60 \pm 34.30$ & $181.00 \pm 45.28$ & $192.20 \pm 18.20$ & 5.459 & $.010^{*}$ & $a<c$ \\
\hline & R:flexion & $80.60 \pm 22.21$ & $94.50 \pm 18.47$ & $108.00 \pm 26.42$ & 3.672 & $.039^{*}$ & $\mathrm{a}<\mathrm{c}$ \\
\hline \multirow{4}{*}{$\begin{array}{l}\text { PT at } 60^{\circ} / \mathrm{sec} \\
(\% \mathrm{BW})\end{array}$} & L:extension & $229.61 \pm 38.77$ & $246.77 \pm 38.00$ & $221.12 \pm 49.37$ & .951 & .399 & \\
\hline & L:flexion & $133.52 \pm 21.67$ & $122.84 \pm 22.42$ & $122.00 \pm 20.07$ & .899 & .419 & \\
\hline & R:extension & $230.76 \pm 40.73$ & $246.33 \pm 44.79$ & $223.56 \pm 42.53$ & .742 & .486 & \\
\hline & R:flexion & $130.79 \pm 32.26$ & $129.68 \pm 19.05$ & $121.97 \pm 17.65$ & .403 & .672 & \\
\hline \multirow{4}{*}{$\begin{array}{l}\text { AP at } 180 \% / s e c \\
\text { (watt) }\end{array}$} & L:extension & $147.50 \pm 25.69$ & $156.20 \pm 32.49$ & $172.20 \pm 44.65$ & 1.269 & .297 & \\
\hline & L:flexion & $102.50 \pm 24.47$ & $90.70 \pm 27.61$ & $100.60 \pm 38.05$ & .429 & .656 & \\
\hline & R:extension & $141.90 \pm 31.06$ & $154.30 \pm 41.17$ & $179.10 \pm 40.31$ & 2.511 & .100 & \\
\hline & R:flexion & $101.90 \pm 29.49$ & $99.00 \pm 33.98$ & $96.40 \pm 34.29$ & .071 & .932 & \\
\hline \multirow{4}{*}{$\begin{array}{l}\mathrm{AP} \text { at } 180 \% \mathrm{sec} \\
(\% \mathrm{BW})\end{array}$} & L:extension & $240.68 \pm 45.28$ & $214.05 \pm 33.93$ & $201.71 \pm 69.76$ & 1.475 & .247 & \\
\hline & L:flexion & $165.50 \pm 31.23$ & $123.85 \pm 34.46$ & $118.77 \pm 58.46$ & 3.533 & $.043^{*}$ & \\
\hline & R:extension & $232.51 \pm 54.34$ & $210.54 \pm 45.33$ & $212.11 \pm 75.74$ & .419 & .662 & \\
\hline & R:flexion & $166.64 \pm 47.28$ & $134.54 \pm 38.08$ & $113.15 \pm 52.00$ & 3.403 & $.048^{*}$ & \\
\hline
\end{tabular}

Values are mean \pm Standard Deviation

PT, peak torque; \%BW, body weight percentage; AP, average power; CJA, cadet judo athletes; JJA, junior judo athletes; SJA, senior judo athletes ${ }^{*} p<.05, * * p<.01, * * * \quad p<.001$ 
et al. 2011), and the maximal strength in bench press of the Brazilian judo players was regulated by cross sectional area and muscle mass of the upper limbs (Franchini et al. 2007). However, Clarys et al. (2011) reported that body fat in judo players did not differ among cadets, junior and senior athletes, and these results are because elite judo athletes who participated in the experiment had the appropriate percentage body fat levels $(10 \sim 15 \%)$ for their weight category (Torres-Luque et al. 2016). Thus, we think that muscle mass and maximal muscle strength of judo athletes might be a critical factor for winning the competition.

Judo is a combat sport that requires high levels of physical capabilities, including anaerobic power, flexibility, maximum muscle strength and endurance (Franchini et al., 2014). Evaluation of physical fitness can classify performance levels and physical conditioning of judo athletes. Thus, many coaches in the field demanded an easy and reliable way to measure various physical fitness, and in 1995, Sterkowicz (1995) developed and proposed the special judo fitness test (SJFT). SJFT has verified to be suitable for identifying of the anaerobic power and recovery rate of judo players, and was similar to the results of Wingate anaerobic test (Casals et al., 2017). In present study, we applied Wingate and basic physical fitness tests to confirm the anaerobic power, muscle strength and muscle endurance of judo athletes. Agility and maximal muscle strength as well as anaerobic power were significantly higher in the SJA group than in the CJA group. According to previous study published by Chycki et al. (2021), muscle strength and anaerobic capacity were an important consideration that has a positive effect on performance in combat sport. And Bonitch-Gongora et al. (2012), Borkowski et. (2001), and Lech et al. (2015) suggested that changes in performance during judo competition was due to reduction of maximal strength of upper and lower extremities. In another previous studies, elite junior and senior judo athletes had a higher index in maximal isometric muscle strength and peak power compared to cadets, and these differences are highly associated with a high level of testosterone, increase in muscle mass and activation of glycolytic metabolism (Agostinho et al., 2018; Nindl et al., 1995). Although it is not possible to conclude performance factors from the results of various previous studies, we believe that maximal strength and anaerobic power abilities can contribute positively to judo competition.

Isokinetic muscle testing has been widely used for finding out muscle strength in athletes and showing the similarity between agonist and antagonist muscles (Willson et al., 2006; Yilmaz et al., 2020). We investigated isokinetic knee functions at $60 \% \mathrm{sec}$ and $180^{\circ} / \mathrm{sec}$, and the SJA group had higher knee extensor and flexor strength compared to the CJA group. In previous study, Ghrairi et al. (2014) used an isokinetic dynamometer to determine the contribution of isokinetic knee muscle strength to judo athletes, and measured at 60, 180 and $240 \%$ sec for the knee. Yilmaz et al. (2020) reported that isokinetic lower and upper extremity strength in elite judo athletes was higher as their performance is excellent. In specific, the isokinetic knee muscle strength obtained at $60 \% \mathrm{sec}$ angular velocity had the highest correlation with judo performance (Ghrairi et al., 2014). Our results regarding changes in isokinetic muscle function of judo athletes was consistent with some previous studies showing that isokinetic concentric strength of the knee should improve with age and athlete experience.

Given these results obtained in present study, anaerobic power, maximal muscle strength and endurance would positively regulate performance of judo athletes with increasing age and athletic experience. Therefore, coaches and trainers in the field should try to provide a periodic training program to increase judo related physical fitness and to succeed. 


\section{References}

Agostinho MF, Junior JAO, Stankovic N, Escobar-Molina R, Franchini E. (2018) Comparison of special judo fitness test and dynamic and isometric judo chin-up tests' performance and classificatory tables' development for cadet and junior athletes. J Exerc Rehabil, 14(2), 244-252.

Artioli, G. G., Iglesias, R. T., Franchini, E., Gualano, B., Kashiwagura, D. B., Solis, M. Y., ... \& Lancha Junior, A. H. (2010). Rapid weight loss followed by recovery time does not affect judo-related performance. Journal of sports sciences, 28(1), 21-32.

Atkinson G, Peacock O, St Clair Gibson A, Tucker R. (2007). Distribution of power output during cycling: impact and mechanisms. Journal of Sports Medicine, 37(8), 647-667.

Baum BS, Li L. (2003). Lower extremity muscle activities during cycling are influenced by load and frequency. Journal of Electromyography and Kinesiology, 13(2), 181-190.

Bentley DJ, McNaughton LR, Thompson D, Vleck VE, Batterham AM. (2001). Peak power output, the lactate threshold, and time trial performance in cyclists. Med Sci Sports Exerc, 33(12), 2077-2081.

Bonitch-Góngora, J. G., Bonitch-Domínguez, J. G., Padial, P., \& Feriche, B. (2012). The effect of lactate concentration on the handgrip strength during judo bouts. The Journal of Strength \& Conditioning Research, 26(7), 1863-1871.

Borkowsky, L. (2001). Evaluation of the aerobic and anaerobic fitness in judoists from the Polish national team. Biol Sport, 18, 107-111.

Branco, B. H., Marcondes, V. A., de Paula Ramos, S., Badilla, P. V., \& Andreato, L. V. (2021). Effects of Supplementary Strength Program on Generic and Specific Physical Fitness in Cadet Judo Athletes. The Journal of Strength \& Conditioning Research.

Brill P W, Couzen G S. (2002). The Core Program, 1st ed, New York: Bantam Books
Burke ER. (1980). Physiological Characteristics of Competitive Cyclists. Phys Sportsmed, 8(7), 78-84. Casals, C., Huertas, J. R., Franchini, E., Sterkowicz-Przybycien, K., Sterkowicz, S., Gutiérrez-García, C., \& Escobar-Molina, R. (2017). Special judo fitness test level and anthropometric profile of elite Spanish judo athletes. The Journal of Strength \& Conditioning Research, 31(5), 1229-1235.

Chycki, J., Zajac, A., \& Toborek, M. (2021). Bicarbonate supplementation via lactate efflux improves anaerobic and cognitive performance in elite combat sport athletes. Biology of Sport, 38(4).

Clarys, P., Geelen, B., Aerenhouts, D., Deriemaeker, P., \& Zinzen, E. (2011). Estimation of body composition in adolescent judo athletes. Journal of Combat Sports and Martial Arts, 2(2), 73-77.

Craig NP, Norton KI. (2001). Characteristics of track cycling. Sports Med, 31(7), 457-68.

Drust B, Rasmussen P, Mohr M, Nielsen B, Nybo L. (2005). Elevations in core and muscle temperature impairs repeated sprint performance. Acta Physiol Scand, 183(2), 181-90.

Faria EW, Parker DL, Faria IE. (2005). The Science of Cycling. Sports Med, 35(4), 313-337

Franchini, E., Brito, C. J., Fukuda, D. H., \& Artioli, G. G. (2014). The physiology of judo-specific training modalities. The Journal of Strength \& Conditioning Research, 28(5), 1474-1481.

Franchini, E., Del Vecchio, F. B., Julio, U. F., Matheus, L., \& Candau, R. (2015). Specificity of performance adaptations to a periodized judo training program. Revista Andaluza de Medicina del Deporte, 8(2), 67-72.

Franchini, E., Nunes, A. V., Moraes, J. M., \& Del Vecchio, F. B. (2007). Physical fitness and anthropometrical profile of the Brazilian male judo team. Journal of physiological anthropology, 26(2), 59-67.

Franchini, E., Rodríguez Huertas, J., Sterkowicz, S., Carratalá, V., Gutiérrez-García, C., \& Escobar Molina, R. (2011). Anthropometrical profile of elite 
Spanish Judoka: Comparative analysis among ages. Archives of Budo, 7(11), 239-245.

Franchini, E., Takito, M. Y., Alves, E. D., Shiroma, S. A., Julio, U. F., \& Humberstone, C. (2019). Effects of different fatigue levels on physiological responses and pacing in judo matches. The Journal of Strength \& Conditioning Research, 33(3), 783-792.

Ghrairi, M., Hammouda, O., \& Malliaropoulos, N. (2014). Muscular strength profile in Tunisian male national judo team. Muscles, ligaments and tendons journal, 4(2), 149.

Gleim GW, Nicholas JA, Webb JN. (1978). Isokinetic Evaluation Following Leg Injuries. Phys Sportsmed, 6(8), 75-82.

Grimby G. (1982). Isokinetic training. Int J Sports Med, 3(l), 61-64.

Haakonssen EC, Barras M, Burke LM, Jenkins DG, Martin DT. (2016). Body composition of female road and track endurance cyclists: Normative values and typical changes. Eur J Sport Sci, 16(6):645-653.

Hansen E A, Raastad T, Hallen J. (2007). Strength training reduces freely chosen pedal rate during submaximal cycling. European Journal of Applied Physiology, 101(4), 419-426.

Hodges P W. (2003). Core stability exercise in chronic low back pain. Orthopedic Clinics of North America, 34(2), 245-254

Howe ST, Bellinger PM, Driller MW, Shing CM, Fell JW. The effect of beta-alanine supplementation on isokinetic force and cycling performance in highly trained cyclists. Int J Sport Nutr Exerc Metab 2013; 23(6):562-70.

Kim JH (2008) Development of physical fitness index and training program for improving the performance of racing cyclists. Korea institute of sport science.

Kons, R. L., Athayde, M. S. D. S., Follmer, B., \& Detanico, D. (2017). Methods and magnitudes of rapid weight loss in judo athletes over pre-competition periods. Human Movement, 18(2),
49-55.

Lee H, Martin DT, Anson JM, Grundy D, Hahn AG. Physiological characteristics of successful mountain bikers and professional road cyclists. J Sports Sci 2002;20(12):1001-1008.

Lech, G., Chwała, W., Ambroży, T., \& Sterkowicz, S. (2015). Muscle torque and its relation to technique, tactics, sports level and age group in judo contestants. Journal of human kinetics, 45, 167.

Lericollais R, Gauthier A, Bessot N, Davenne D. (2011). Diurnal evolution of cycling biomechanical parameters during a 60-s Wingate test. Anne. Scand J Med Sci Sports, 21(6), e106-14.

Martin DT, McLean B, Trewin C, Lee H, Victor J, Hahn AG. (2001). Physiological characteristics of nationally competitive female road cyclists and demands of competition. Sports Med, 31(7), 469-77.

Marques, L., Franchini, E., Drago, G., Aoki, M. S., \& Moreira, A. (2017). Physiological and performance changes in national and international judo athletes during block periodization training. Biology of sport, 34(4), 371.

Nindl BC, Mahar MT, Harman EA, Patton JF. (1995) Lower and upper body anaerobic performance in male and female adolescent athletes. Med Sci Sports Exerc. 27(2), 235-41.

Oded Bar-Or. (1987). The Wingate anaerobic test. An update on methodology, reliability and validity. Sports Med, 4(6):381-94.

Old T. (2001). Human locomotion: Application to Cycling. Sports Med, 31(7), 497-509.

Redfield R, Hull ML. (1986). On the relation between joint moments and pedalling rates at constant power in bicycling. J Biomech, 19(4), 317-29.

Redfield R, Hull ML. (1986). Prediction of pedal forces in bicycling using optimization methods. $J$ Biomech, 19(7), 523-40.

Rønnestad BR, Hansen J, Hollan I, Ellefsen S. (2015). Strength training improves performance and pedaling characteristics in elite cyclists. Scand $J$ 
Med Sci Sports, 25(1), e89-98.

Sakamoto A, Naito H, Chow CM. (2018). Effects of Hyperventilation on Repeated Pedaling Sprint Performance: Short vs. Long Intervention Duration. J Strength Cond Res, 32(1), 170-180

Sterkowicz, S. (1995). Test specjalnej sprawnoci ruchowej w judo. Antropomotoryka, 12, 29-44.

Sterkowicz-Przybycień K, Miarka B, Fukuda DH. (2017). Sex and Weight Category Differences in Time-Motion Analysis of Elite Judo Athletes: Implications for Assessment and Training. $J$ Strength Cond Res, 31(3), 817-825.

Torres-Luque, G., Hernández-García, R., Escobar-Molina, R., Garatachea, N., \& Nikolaidis, P. T. (2016). Physical and physiological characteristics of judo athletes: An update. Sports, 4(1), 20.

Van Soest AJ, Casius LJ. (2000). Which factors determine the optimal pedaling rate in sprint cycling?. Med Sci Sports Exerc, 32(11), 1927-34.

Vikmoen O, Ellefsen S, Trøen Ø, Hollan I, Hanestadhaugen M, Raastad T, Rønnestad BR. (2016). Strength training improves cycling performance, fractional utilization of $\mathrm{VO} 2 \mathrm{max}$ and cycling economy in female cyclists. Scand J Med Sci Sports, 26(4), 384-396.

Willdson JD, Dougherty CP, Ireand ML, Davis IM. (2005). Core stability and its relationship to lower extremity function and injury. The Journal of the American Academy of Orthopaedic Surgeons, 13(5), 16-25.

Willson JD, Ireland ML, Davis IM. (2006). Core strength and lower extremity alignment during single leg squat. Medicine and Science in Sports Exercise, 38(5), 945-952.

Yılmaz, A. K., Ermiş, E., Kabadayı, M., \& Bostancı, Ö. (2020). Correlation of Upper and Lower Extremities Isokinetic Strength in Elite Male Judokas. Journal of Men's Health, 16(4), e141-e152.

Zhao, K., Hohmann, A., Chang, Y., Zhang, B., Pion, J., \& Gao, B. (2019). Physiological, anthropometric, and motor characteristics of elite Chinese youth athletes from six different sports. Frontiers in physiology, 10, 405. 